\title{
Cutaneous leishmaniasis caused by Leishmania major in Morocco: still a topical question
}

\author{
M. Riyad, ${ }^{1}$ S. Chiheb ${ }^{7}$ and M. Soussi-Abdallaoui ${ }^{7}$
}

$$
\text { دريم رياض، الليشمانيات الجمية شهاب، الناجم عن الليشهانية الكبيرة في المغرب: لايز ال يمثّل مشكلة مدارية }
$$

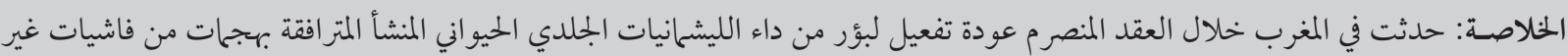

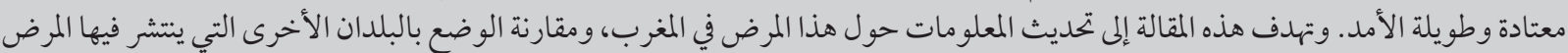

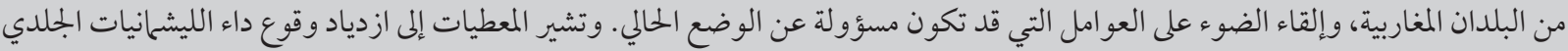

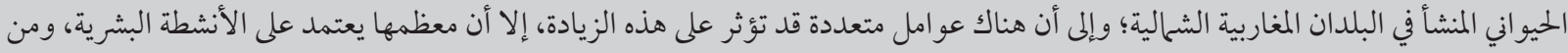

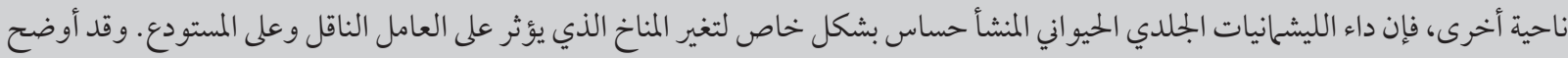

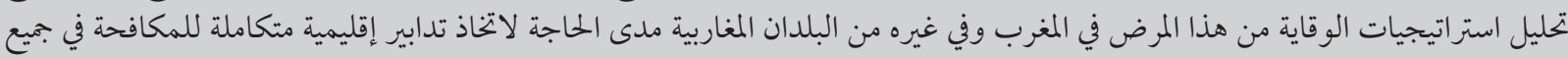

بلدان الإقليم.

ABSTRACT In the past decade in Morocco, there has been a reactivation of zoonotic cutaneous leishmaniasis (ZCL) foci with an unusual long outbreak episode. The aims of this review article were to update our knowledge of this disease in Morocco, to compare the situation with that prevailing in the other countries of the Maghreb region and to highlight factors that could be responsible for the current situation. The data indicate a global increase of ZCL incidence in the other Maghreb countries. Several factors could be influencing this increase but most of them will depend on human activities. On the other hand, ZCL is particularly sensitive to climate changes acting on the vector and the reservoir. An analysis of prevention strategies against the disease in Morocco and the other Maghreb countries highlights the need for integrated regional control measures in all the countries of the region.

Leishmaniose cutanée due à Leishmania major au Maroc : une question encore d'actualité

RÉSUMÉ Au cours des dix dernières années au Maroc, on a observé une réactivation des foyers de leishmaniose cutanée zoonosique, caractérisée par une période de flambée inhabituellement longue. Le présent article de synthèse a pour objectif d'actualiser nos connaissances sur cette maladie au Maroc, de comparer la situation avec celle qui prévaut dans les autres pays de la région du Maghreb et de mettre en évidence les facteurs qui pourraient être responsables de la situation actuelle. Les données indiquent une augmentation de l'incidence globale de la leishmaniose cutanée zoonosique dans les autres pays du Maghreb. Plusieurs facteurs pourraient influer sur cette augmentation mais la plupart d'entre eux dépendent des activités humaines. En outre, la leishmaniose cutanée zoonosique est particulièrement sensible aux changements climatiques ayant un impact sur le vecteur et le réservoir. Une analyse des stratégies de prévention de cette maladie au Maroc et dans d'autres pays du Maghreb met en évidence la nécessité de mesures de lutte régionales intégrées dans tous les pays de la Région. 


\section{Introduction}

Cutaneous leishmaniasis (CL) is endemic in over 80 countries worldwide, with an annual incidence of about 1.5 to 2 million cases [1]. In some countries of the Eastern Mediterranean region (EMR) leishmaniasis is considered as an important health problem because of its impact on morbidity and its potential to spread in epidemics, which create a heavy burden on national health services [2]. Among the 22 EMR countries, 14 report both cutaneous and visceral forms of leishmaniasis, and in 2008 around 100000 new cases of CL were notified [3].

Zoonotic CL (ZCL) is an important health problem in many countries of the southern and eastern Mediterranean, with varied clinical manifestations from simple and single lesions to disseminated lesions [4]. Despite the spontaneous healing of these lesions, the facial scars can be a social stigma, especially for women. On the southern shore of the Mediterranean basin, ZCL is historically the first form described and is predominant in the Maghreb region [5-7]. In Morocco, sporadic cases of ZCL have been described since 1914, and epidemic foci appeared in the late 1970s [5,8-10]. In recent decades, and in spite of a dedicated national programme to fight leishmaniases, there has been a reactivation of ZCL foci, which has been characterized by longer outbreaks. Nevertheless, the related Moroccan literature is poor, consisting of national reports from the Ministry of Health and sporadic research articles.

Through a literature review we aimed to update the knowledge of this disease in Morocco, to compare the situation prevailing in the other countries of the Maghreb region and to highlight the factors that could be responsible for the current situation.

\section{Methods}

In order to search for publications related to our topic we mainly used the PubMed and Science Direct search engines. We tried several sets of keywords in order to cover most papers dedicated to the epidemiology ofZCL in general and in specific countries and risk factors and prevention strategies. We used no date limitations. We began with the $\mathrm{MeSH}$ terms "leishmaniasis cutaneous", and then entered several combinations of the following keywords: "leishmaniasis", "leishmaniases" "cutaneous", "zoonotic", "leishmania", "major", "old world", "Morocco", "Algeria", "Tunisia”, "Libya”, "Mauritania", "risk factors", "climate", "fight" and "strategies". Overall more than 7000 papers related to cutaneous leishmaniasis were browsed. We refined the selection by entering several combinations of the above keywords. The first rough selection was made from the titles and dates of the papers and if necessary from the abstracts. Finally, we selected the most pertinent articles according to our aims. We also used the reports from the World Health Organization (WHO) and the Ministry of Health in Morocco.

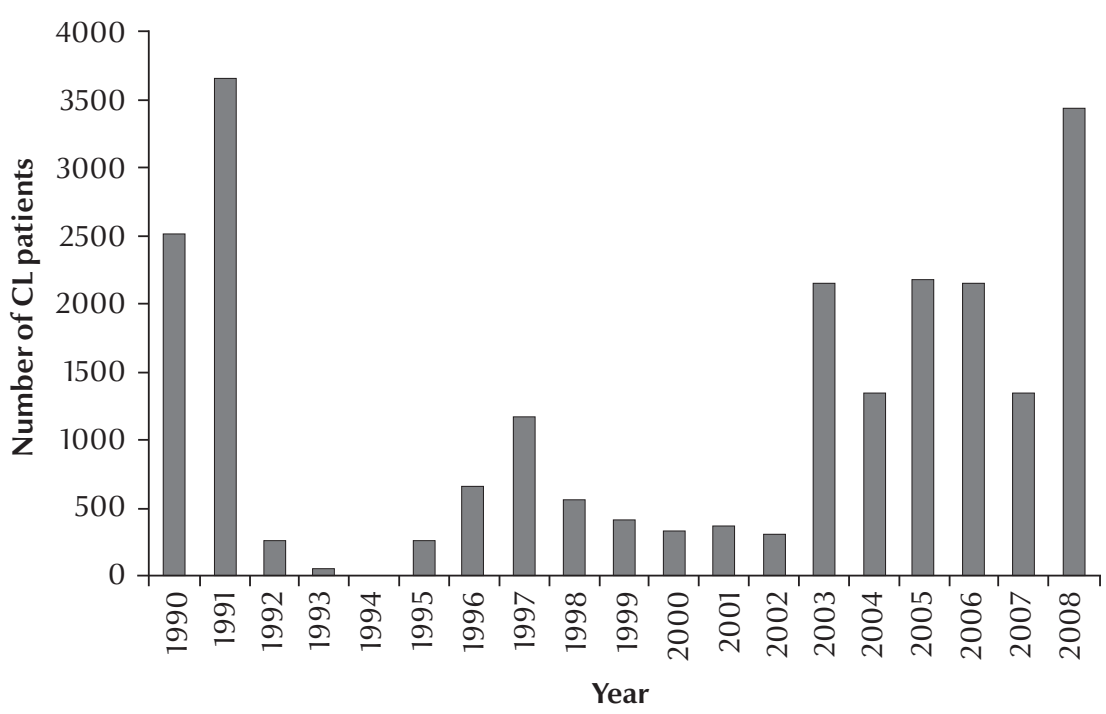

Figure 1 Annual incidence of cutaneous leishmaniasis due to Leishmania major in Morocco, 1990-2008 
mountains were involved [12]. However, the particular feature of this last decade was the unusual persistence of the epidemics (Figure 1), with annual and regional fluctuations in incidence, with values reaching up to 953 cases per 100000 inhabitants in some eastern rural areas in 2006 [12]. Moreover, despite a slight female predominance, all ages were affected, thus highlighting the current epidemic situation of the disease.

The analysis of the annual evolution of confirmed CL patients infected in $L$. major foci and consulting at the department of dermatology at Ibn Rochd Hospital, Casablanca, seems to reflect the national tendency; generally these patients live in Casablanca city and return to their rural birthplaces during the summer holidays (unpublished data).

In Morocco, L. major MON-25 is the only zymodeme found in the southern palm groves, and the vectorial role of Phlebotomus papatasi is well demonstrated $[5,8]$. The reservoir of the parasite is a rodent, Meriones shawi grandis, commonly called the sand rat. This host appeared to adapt to synanthropic behaviour by modification of its nutritional requirements (it became coprophagous and detritivorous), and hence contributed to the increase of ZCL incidence in Morocco [2, Rioux et al. unpublished data]. In the north of the Eastern highlands, M. shawi becomes scarce and is substituted by another Gerbillidae, Psammomys obesus $[5,8,13]$.

In humans, the disease usually presents as multiple ulcerated and vegetant lesions that often are infected; they are located on the face and more often on the limbs. The incubation period is relatively short (2-3 months), and over $90 \%$ of the cases are reported during the 1 st and 4th quarters of the year, which is a feature of the summer-autumn transmission of CL due to L. major. The healing occurs spontaneously in 4-6 months $[8,14]$.

\section{Zoonotic cutaneous leishmaniasis caused by $\mathrm{L}$ major in the other northern Maghreb countries}

L. major MON-25 remains the zymodeme predominantly observed in the Maghreb $[6,8,15,16]$. These countries also share the same vector, $P$ h. papatasi, characterized by its wide geographical distribution in these arid regions, with a very little genetic variability and often a synanthropic behaviour [3]. Moreover, if $M$. shawi grandis is the major reservoir for L. major in Morocco, it seems that Ps. obesus is providing this role in the other countries of the Maghreb, Algeria, Tunisia and Libya $[3,5,6,8,15]$.

In these other Maghreb countries, the extension and the emergence of new foci has also been reported. Thus, in Algeria, CL due to L. major is an old disorder, reported since 1921 [7]. This country is one of the most affected countries in the world $[7,15]$. Between 2000 and 2005, almost all of the reported cases were caused by L. major and the foci extended geographically, starting at the known southern foci towards the Algerian highlands in the north $[7,15]$. During epidemics the annual number of new cases of ZCL exceeded 10000 cases per year. The urbanization of the disease has been noted because of the urban extensions to the suburbs [7]. In general, the boundaries between the different nosogeographical forms of leishmaniases overlap and progress in Algeria [Boudrissa A et al. unpublished data].

In Tunisia, CL has been reported since 1884 ("bouton de gafsa", "bobinet duperet") [6]. Central Tunisia has always been free from the "oriental sore" until the outbreak of a major epidemic in 1982 in the region of Sidi Saad in Kairouan governorate in the vicinity of a new dam [4]. It was followed by a secondary extension in the centre and the south of the country, where the annual incidence often exceeded 3000 to 5000 cases per year. Since 2002 almost half of the governorates are considered endemic areas $[4,17]$.

In Libya, L. major CL is endemic in the north-west. Actually, an extension of the epidemic foci from the east towards the west is reported [Fathy FM et al., unpublished data]. In the emerging focus of Sirte, the majority of lesions are multiple and active for up to 2 months, with a predominance $(77.3 \%)$ of the ulcerative forms [18].

\section{Discussion}

\section{Epidemiological situation in the region}

While there is a global increased incidence of CL in the Maghreb countries, no new macro-focus has emerged in Morocco, although we can note that the maintenance of the epidemic phase covers an unusually long period and a greater number of rural communities are affected. The Atlas mountains are likely a geographical barrier to the spread of ZCL foci to the north of Morocco. Indeed it has been shown that the greatest abundance of P. papatasi is observed in hyper-arid bioclimates and is characterized by a negative correlation with the altitude, with peak densities observed in the plains (400 to $599 \mathrm{~m}$ ) $[19,20]$. On the other hand, in Algeria, the foci extended geographically during the 2000s from the south towards the northern Algerian highlands [7,15]. In Libya, $L$. major $C L$ is actually extending from the eastern endemic foci towards the west [Fathy FM et al., unpublished data].

\section{Factors associated with the increase in incidence of leishmaniases}

Several factors can influence the incidence of leishmaniases in a given area. However, most of these will depend on human activities, such as environmental changes, migration of non-immune populations, development of agricultural and industrial projects, military 
activities and urbanization [2,21]. These are summarized in Figure 2.

In Tunisia, the ecological changes brought about by the development of hydraulic structures in the late 1970s, and the extensive agricultural programmes in the centre-south of the country, have probably contributed to the proliferation of sandflies and rodent populations due to the change of temperature and soil moisture. Accordingly, the construction of the Sidi Saad dam was followed by the expansion of Chenopodiaceae plants, which are the exclusive diet for $P$. obesus, the $L$. major reservoir in Tunisia. In addition, the drilling of numerous wells have increased moisture in other regions and induced an increase in the vector $P$. papatasi density, thus exposing humans to a greater transmission risk $[2,4,6,22]$.

In Libya, Saudi Arabia and the Syrian Arab Republic, the increasing incidence of leishmaniasis is also associated with human population movements caused by new irrigation programmes $[2,22]$. Urbanization is a major risk factor, not only because it is often carried out in a disorderly way in these countries, but also because it results in the intrusion of urban residential areas into outlying rural areas that were previously occupied only by the vector and the reservoir of the parasite. In Saudi Arabia, this situation had led to an increased transmission to humans in some eastern cities of the country $[1,22]$.

In Morocco, the ZCL epidemics curve shows peaks and an inter-epidemic periodicity of 5-6 years. The factors influencing the spatial and temporal dynamics are not well understood and there might be several factors, such as the dynamics of rodent populations, the dispersal of vectors, climate changes, the vegetation and the soil type, but also the dense human populations settlements in areas where the sylvatic transmission of leishmaniasis is high (rodent-vector-rodent cycle). Indeed, the circulation of the parasite is directly dependent on the biotope structure and the hosts' ethology [4, Rioux JA et al. unpublished data]. In Morocco, in the south-eastern provinces of Ouarzazate and Tata (tourist areas), the main causes of transmission are the planning of immense tracts of land for agricultural, industrial or tourist developments [13]. However, Boussaa et al. recently showed that among the sandflies collected in the prefecture of Marrakesh, another tourist area [23], P. papatasi was the species least affected by the habitat type and in particular by urban developments. Interestingly, despite the high density of $P$. papatasi, the omnipresence of the animal reservoir (M. shawi), and the settlement of human populations arriving from neighbouring ZCL foci, up to now no active local transmission of L. major has been notified in Marrakesh $[12,23,24]$. Thus the changing pattern of ZCL in Morocco could not been explained solely by increasing urbanization and we should look for other factors.

Climate undoubtedly has an influence on the emergence and re-emergence of human infectious diseases, in particular on vector-borne diseases [2]. Weather changes indirectly affect food production and the overall level of human populations; these two factors will in turn lead to population movements. Among the different forms of Mediterranean leishmaniases, ZCL is the one whose response to climate change depends on either the vector and/or the rodent, both of which are influenced by

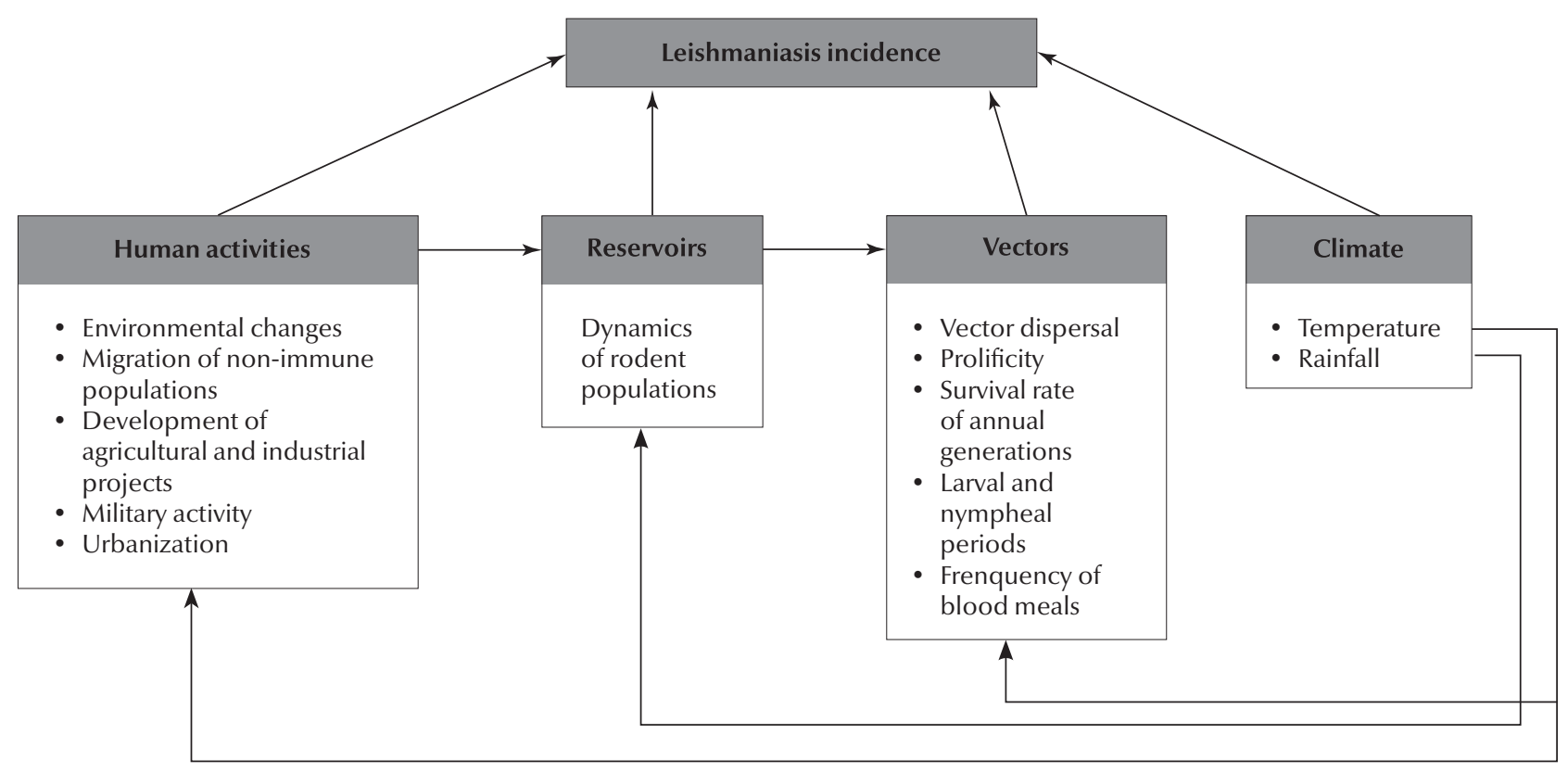


the climate [25]. Indeed climate can affect the vector density, which has direct repercussions on the CL transmission dynamics, the parasite development time within vectors or even on its vector competence [20,25-27]. In southwest Asia a temperature rise of $1-5$ ${ }^{\circ} \mathrm{C}$ due to global warming could be further responsible for the expanding range of $P$. papatasi and thus for the increased transmission of L. major [19]: an ambient temperature rise increases the prolificity, the daily survival rate, the number of annual generations and reduces larval and nympheal periods, but it also increases the activity and frequency of blood meals, thus facilitating the transmission of vector-borne diseases [25].

Finally, changes in seasonal rainfall patterns might have a major impact on the running of some epidemiological systems [25]. In Sudan, the epidemic of CL that occurred in Khartoum between 1985 and 1986 was probably the consequence of a very wet episode that generated the ideal breeding conditions for sandflies [2].

\section{Prevention strategies for zoonotic cutaneous leishmaniasis}

In the EMR, prevention strategies are based mainly on vector and reservoir control measures; this latter component being very important. In Jordan and Tunisia, actions to induce environmental changes, such as destroying P. obesus burrows and chenopods and planting trees around human habitations, have significantly contributed to the fall in the incidence of the disease among human populations [2].

In Morocco, regular surveillance of rodents is carried out in the regions affected by ZCL due to L. major. The preventive and control measures against the rodent reservoirs are then evaluated comparing rodent densities before and after treatment [11]. The measures for control of vectors and prevention of rodent infestations are carried out throughout the year in human urban centres and are based on improving hygiene conditions and the promotion of rat-proofing measures. All these actions are supported by education and raising public awareness. The chemical measures for controlling rodent populations are programmed during the low-density phases of the rodents and involve the collaboration of local collectives and associations. They involve peridomestic use of rodenticides in the active burrows in all infested areas.

These data clearly show the value of integrated prevention programmes that involve different national sectors: health, tourism, public works, local authorities and local collectives and associations. However, successful control measures will depend not only on the understanding of the epidemiology of leishmaniasis, for instance indoors insecticides will not be effective if the vector species is exophilic or exophagic [2]. Furthermore, the sociocultural habits of the human populations exposed are also important. Thus the control units involved must be aware of the possible constraints imposed on people exposed to the disease.

In Morocco, the fight against rodents by improving waste disposal measures before chemical treatment is done in collaboration with local populations [11]. However, in spite of this, the current outbreaks of ZCL beg the question of the adequacy of the control measures applied in the field against rodents. Indeed, chemical methods usually used against domestic rodents are not always effective against wild rodents; in the case of P. obesus, physical measures are more effective [3]. Hence the interest of identifying and following the dynamics of all the rodent species that are potential reservoirs of L. major, especially when the epidemiological situation is changing or deteriorating. Furthermore, like it has been suggested in Sudan that ZCL due to L. major could be being maintained through an anthroponotic transmission; the short duration of cutaneous lesions does not affect the parasite survival when the vector is active throughout the year [3].

In Morocco, Rioux et al. suggested that leishmaniasis risk areas could be delineated based on vector densities in the different bioclimatic areas [5, Rioux JA et al. unpublished data]. In 1984, they suggested that the arid plain of Marrakesh (located near known active foci of ZCL and anthroponotic CL) and especially its western part might be significant risk areas in spite of the absence of notified active CL cases. Recently Boussaa et al. have shown that in this region, P. papatasi was the predominant sandfly species and was active all the year in the urban areas [28].

Finally, the documented prevention strategies are essentially focused on the reservoirs; the easiest and least expensive measures inducing environmental changes will lead to decreases in rodent densities (Figure 3). Hygiene promotion through the education of local populations is important, but this must be promoted by local authorities. However, all these actions against rodents rely on a good knowledge of the rodent populations living and circulating in the known foci, hence the need for a scientific surveillance of rodent populations. It is evident that a decrease in the reservoir populations will have a direct negative impact on vector densities and then on the disease itself.

\section{Conclusion}

In Morocco, ZCL still remains a public health problem with a persistent epidemic episode during the last decade. Different factors may be responsible for the increased incidence of ZCL. 


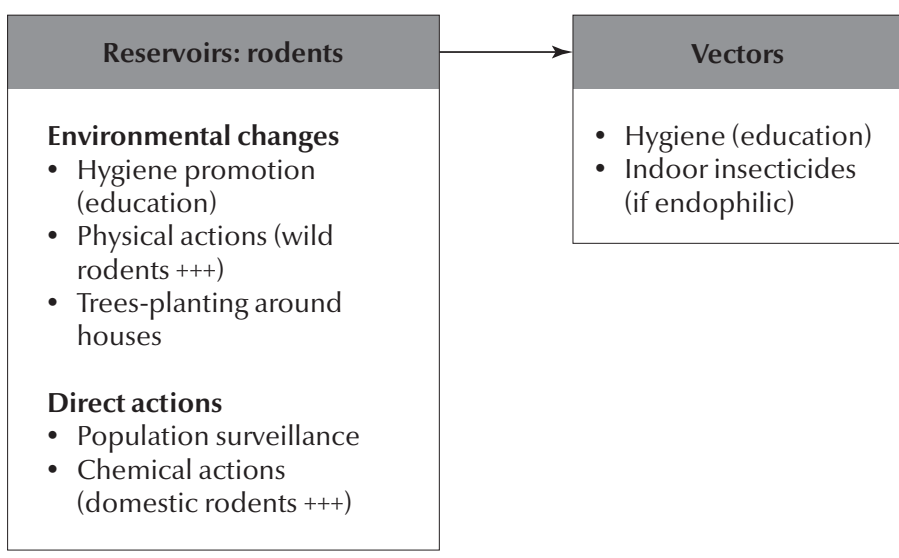

Figure 3 Main prevention strategies for zoonotic cutaneous leishmaniasis

Climate changes have a direct impact on pathogens and vectors, and thus might increase the exposure of human and animal populations to ZCL, and then result in changes in the geographical distribution. On the other hand, all the elements generating population movements such as socioeconomic factors are also of major importance in the maintenance and emergence/ re-emergence of ZCL foci. Thus national cross-sector collaboration is a key element in the success of national control measures taken against the disease. Furthermore, given the similarity of ZCL foci in the Maghreb, this problem could also be solved through a strong involvement of governments, by improving diagnosis, notification systems, treatment and research through national reference centres with multidisciplinary teams, and through regional control measures.

Finally, in our view, the estimation of leishmaniasis risk is of interest particularly in areas where different planning and development programmes are scheduled. Also, the modelling of ZCL could allow the prediction of epidemic peaks and the geographical expansion. For this, the understanding of the epidemiological characteristics of ZCL, and the assessment of its critical parameters are mandatory.

Competing interests: None declared.

\section{References}

1. World Health Organization. Urbanization: an increasing risk factor for leishmaniasis. Weekly Epidemiological Record, 2002, 77:365-372.

2. Neouimine NI. Leishmaniasis in the Eastern Mediterranean region. Eastern Mediterranean Health Journal, 1996, 2(1):94-101.

3. Ruiz Postigo JA. Leishmaniasis in the World Health Organization Eastern Mediterranean region. International Journal of Antimicrobial Agents, 2010, 36S:S62-S65.

4. Ben Salah A et al. Zoonotic cutaneous leishmaniasis in central Tunisia: spatio-temporal dynamics. International Journal of Epidemiology, 2007, 36:991-1000.

5. Rioux JA et al. Les leishmanioses cutanées du bassin méditerranéen occidental. De l'identification enzymatique à l'analyse éco-épidémiologique. L'exemple de trois «foyers », tunisien, marocain et français. In: Rioux J, ed. Leishmania, taxonomy and phylogeny, applications to ecology and epidemiology. International colloquium, CNRS/INSERM/WHO, 2-6 July 1984. Montpellier, France, Institut de Recherche pour le Développement, 1986:365-395.

6. Ben Ismail R, Ben Rachid MS. Epidémiologie des leishmaA nioses en Tunisie. Chapter 9. In: Association des Universités Partiellement ou Entièrement de Langue Française-Université des Réseaux d'Expression Française, eds. Maladies tropicales transmissibles. Paris, John Libbey Eurotext, 1989:73-80.

7. Achour Barbich N, Madiou M. [Outbreak of cutaneous leishmaniasis: about 213 cases in the province of Tizi-Ouzou.] Recrudescence des leishmanioses cutanées : à propos de 213 cas dans la wilaya de Tizi-Ouzou. Pathologie Biologie, 2009, 57:65-70.

8. Rioux JA. Eco-épidémiologie des leishmanioses au Maroc: bilan de 30 ans de coopération. (Bulletin Epidémiologique No. 37).
Rabat, Ministère de la Santé du Royaume du Maroc, Direction de l'Epidémiologie et de la Lutte contre les Maladies, 1999.

9. État d'avancement des programmes de lutte contre les maladies parasitaires : rapport annuel d'activités. Rabat, Ministère de la Santé du Royaume du Maroc, Direction de l'Epidémiologie et de la Lutte contre les Maladies, 1999.

10. Rhajaoui M et al. New clinico-epidemiologic profile of cutaneous leishmaniasis, Morocco. Emerging Infectious Diseases, 2007, 13:1358-1360.

11. Lutte contre les leishmanioses, guide des activités. Rabat, Ministère de la Santé du Royaume du Maroc, Direction de l'Epidémiologie et de Lutte contre les Maladies. 2010.

12. État d'avancement des programmes de lutte contre les maladies parasitaires : rapport annuel d'activités. Rabat, Ministère de la Santé du Royaume du Maroc, Direction de l'Epidémiologie et de la Lutte contre les Maladies, 2007.

13. Les leishmanioses au Maroc, de l'analyse éco-épidémiologique à la prévention. Bulletin Epidémiologique No. 7(Supplé.). Rabat, Ministère de la Santé du Royaume du Maroc, Direction de I'Epidémiologie et de la Lutte contre les Maladies, 1992

14. Murray HW et al. Advances in leishmaniasis. Lancet, 2005, 366:1561-1577.

15. Harrat $Z$ et al. Leishmania infantum and L. major in Algeria. Transactions of the Royal Society of Tropical Medicine and $\mathrm{Hy}$ giene, 1996, 90:625-629.

16. Pratlong F et al. Geographical distribution and epidemiological features of Old World cutaneous leishmaniasis foci, based on the isoenzyme analysis of 1048 strains. Tropical Medicine and International Health, 2009, 14:1071-1085.

17. Aoun $\mathrm{K}$ et al. [Epidemiology of Leishmania (L.) infantum, L. major and L. killicki in Tunisia: results and analysis of the iden- 
tification of 226 human and canine isolates.] Epidémiologie de Leishmania (L.) infantum, L. major, et L. killicki en Tunisie: résultats et analyse de l'identification de 226 isolats humains et canins et revue de la littérature. Bulletin de la Société de Pathologie Exotique, 2008, 101:323-328.

18. Fathy FM, El-Kasah F, El-Ahwal AM. Emerging cutaneous leishmaniasis in Sirte-Libya: epidemiology, recognition and management. Journal of the Egyptian Society of Parasitology, 2009, 39:881-905.

19. Guernaoui S, Boumezzough A, Laamrani A. Altitudinal structuring of sandflies (Diptera : Psychodidae) in the High Atlas mountains (Morocco) and is relation to the risk of leishmaniasis transmission. Acta Tropica, 2006, 97:346-351.

20. De La Rocque S, Rioux JA, Slingenbergh J. Climate change: effects on animal disease systems and implications for surveillance and control. Revue Scientifique et Technique-Office International des Epizooties, 2008; 27:339-354.

21. Izri A, Depaquit J, Parola P. [Phlebotomine sandflies and transmission of disease agents around the Mediterranean basin.] Phlébotomes et transmission d'agents pathogènes autour du bassin méditerranéen. Medecine Tropicale, 2006, 66:429-435.
22. Desjeux P. The increase in risk factors for leishmaniasis worldwide. Transactions of the Royal Society of Tropical Medicine and Hygiene, 2001, 95:239-243.

23. Boussaa S, Pesson B, Boumezzough B. Phlebotomine sandflies (Diptera: Psychodidae) of Marrakech city, Morocco. Annals of Tropical Medicine and Parasitology, 2007, 101:715-724.

24. Boussaa $S$ et al. Isoenzymatic characterization of Phlebotomus papatasi (Diptera: Psychodidae) of the Marrakech area, Morocco. Journal of Medical Entomology, 2008, 45:370-374.

25. De La Rocque S, Rioux JA. Influence des changements climatiques sur l'épidémiologie des maladies transmissibles. Bulletin de la Société de Pathologie Exotique, 2008, 101:213-219.

26. Chaves LF, Pascual M. Climate cycles and forecasts of cutaneous leishmaniasis, a nonstationary vector-borne disease. PLoS Medicine, 2006, 3:1320-1328.

27. Cazelles B, Hales S. Infectious diseases, climate influences, and nonstationarity. PLoS Medicine, 2006, 3:1212-1213.

28. Boussaa $\mathrm{S}$ et al. Seasonal fluctuations of phlebotomine sand fly populations (Diptera: Psychodidae) in the urban area of Marrakech, Morocco. Acta Tropica, 2005, 95:86-91. 